\title{
Assessment of Risk Factorsrelated to Hypothyroidism for Adult Patient at Bagdad Teaching Hospitals
}

\author{
Ahmed FleihHassen ${ }^{1}$, Dr. Sabah Abbas Ahmed ${ }^{2}$ \\ ${ }^{1}$ Msc/ Uuniversity of Baghdad /College of Nursing.Adult Nursing Department. \\ ${ }^{2}$ PhD Assistant Professor/University of Baghdad/College of Nursing / Adult Nursing Department.
}

\begin{abstract}
:
The objective are To assess of contributing factors related tohypothyroidismfor adultpatients, and find out the relationship between some demographic characteristic (age, gender, level of education) with risk factors. Methodology: A descriptive study was conducted at theoutpatient consultation in Bagdad teaching hospitals the period between October 2014 to May 2015in order to assess the risk factors related to Hypothyroidism for adult patient at Bagdad Teaching Hospitals .A random sample consistedof (50) patients from suffering hypothyroidism who were systematically admitted to the outpatient consultation were selected one by one. A questionnaire was constructed for the purpose of the study, which is comprised of three parts that include :(1) Sociodemographic Characteristics data(2)The past medical history for patient and family(3) Assessment of risk factors related to diet, psychological factors, social factors and medication .Content validity of the questionnaire was determine through a panel of (14) experts. Reliability and validity of questionnaire was determined through test re-test $(r=0.861)$ of pilot study. Data was collected by the researcher who interviewed those patients and filled out the constructed questionnaire form. Data were analyzed by using descriptive statistical approach (frequency, percentage and mean of score) and inferential statistical approach (stander deviation and correlation coefficient).

Results: The study findings indicated that there is highly significant difference between Women and man the incidence of hypothyroidism disease more than female. It is aged between (28-37) years old for hypothyroidism patients, the most of study sample primary graduates and urban setting. Our results also show that there is significant difference between history of thyroid disease patient and non-history of thyroid disease patients.

Conclusion: from the study that past history of thyroid disease raises the risk to develop hypothyroidism disease.

Recommendations: The study recommends that the further research aimed at established the new department for early detection hypothyroidism for adult patientand education program for nurses to improve the patient quality of life.
\end{abstract}

Keyword: Risk factors, Hypothyroidism.

\section{Introduction}

Worldwide about one billion individuals are estimated to be iodine deficient; however, it is unknown how often this leads to hypothyroidism. In large population-based studies in Western countries with deficiency dietary iodine, $0.3-0.4 \%$ of the population haveovert hypothyroidism. A larger proportion, $4.3-8.5 \%$, has subclinical hypothyroidism ${ }^{(1)}$. Hypothyroidism is the production of an imbalance of thyroid hormone. Hypothyroidism is simply insufficiency thyroid hormone either imbalance affects the metabolism in the body. Guyton (2000) says "hypothyroidism like hyperthyroidism is probably initiated by autoimmunity against the thyroid gland, but immunity that destructs the gland rather than stimulates it. The thyroid gland regulates the body's metabolism, heart rate, blood pressure, and body temperature, among other functions. Thyroid hormone maintains the rate at which your body uses fats and carbohydrates, burn calories, assist regulate body temperature, influence heart rate and helps in controlling the production of protein. Sometimes the thyroid can produce too much hormones or insufficiency ${ }^{(2)}$. Women are most probability to develop hypothyroidism than men. In population-based studies, women were seven times more likely than men to have TSH levels over 10 $\mathrm{mU} / \mathrm{l}^{(3)}$. Many risk factors predispose women and man to hypothyroidismincluding autoimmune thyroid disease (AITD), type (1) diabetes mellitus, other endocrine deficiencies, Down syndrome, thalassemia major, thyroid ablation and who are treated with pituitary surgery or irradiation, head and neck irradiation, treatment of growth hormone deficiency, cytotoxic therapy, lithium, interferon $\alpha$, interferon $\beta$, and therapeutic monoclonal antibodies. Patients with a family or client history of thyroid disease, goiter, history of spontaneous abortion in women, Positive thyroid peroxidase antibody, origin from areas of endemic iodine deficiency, Previous thyroid disease or surgery, or any symptoms suggesting at higher risk for hypothyroidism and hyperthyroidism ${ }^{(4)}$. 


\section{Objectives of the Study}

1. To assessrisk factors related to hypothyroidism for adult patients.

2. To find out the relationships between risk factors related to hypothyroidismand adult patients' certain variables such as (age, gender, educational level).

\section{Methodology}

A descriptive study was carried out throughout the present study to assessment risk factors related tohypothyroidism for adult patients who attended the outpatient consultation of Baghdad Teaching Hospital. The study was carried out during the period extended from the ofOctober $28^{\text {th }} 2014$ to May $15^{\text {th }}$ 2015. The sample consisted of (50) patients hypothyroidism. These patients were attending out patient's consultation of Baghdad Teaching Hospitals(Al- Yarmouk Teaching Hospital, Baghdad Teaching Hospital, AL. KindlyTeaching Hospital and Medical CityKazimain(peace be upon them). A questionnaire- interview format was designed and developed by the researcher for the purpose of the study; such development was employed through the available literature, clinical background and interview with patients who hypothyroidism. All the items were measured on scale of (3) indicates that the always 1, sometimes 2, never 3.Diet domain; daily 3, Weekly 2, mouthly 1 for hypothyroidism .The questionnaire consisted of (3) parts. Part I: Demographic Information Sheet. Part II :historical information satisfactory to the patient and family. Part III:-Risk factors domainWhich include: diet,Psychological domain,social andMedication domain.Rating scale was used to rate the frequency and extension of the problems.The content validity of the instrument was established through a panel of (14) experts.Test- retest reliability was determined through a computation of Pearson Correlations for the scales. Coefficients for the (43) items of risk factors of hypothyroidism were $(\mathrm{r}=0.861)$ for the total score of risk factors. The data were collected by using the questionnaire structured format through interview technique. Each patient was interviewed personally by the researcher. Throughout each interview explanation of the study was held up with patient in order to accept participation. Each interview took approximately from (20-30) minute and initiated at the waiting room. Data were collected between 8.30 am to $1.30 \mathrm{pm}$. The determination was conducted during the period fromJanuary $13^{\text {th }}$ to April $5^{\text {th }}$ 2015.The data were analyzed through descriptive data analysis and inferential data analysis the data were analyzed through the use of Statistical Package of Social Sciences (SPSS) version 16.0.

\section{Results}

Table (1): Distribution of the study Samples by Socio-Demographic Characteristics.

\begin{tabular}{|c|c|c|c|c|}
\hline No. & variables & Groups & Freq. & Percent \\
\hline \multirow{2}{*}{1.} & \multirow{2}{*}{ Gender } & Male & 2 & 4.0 \\
\hline & & Female & 48 & 96.0 \\
\hline \multirow[t]{5}{*}{2.} & \multirow{5}{*}{$\begin{array}{l}\text { Age Groups } \\
\text { (Per years) }\end{array}$} & $18-27$ years & 10 & 20.0 \\
\hline & & $28-37$ years & 16 & 32.0 \\
\hline & & $38-47$ years & 12 & 24.0 \\
\hline & & $48-57$ years & 9 & 18.0 \\
\hline & & $58-67$ years & 3 & 6.0 \\
\hline \multirow[t]{2}{*}{3.} & \multirow[t]{2}{*}{ Residence } & Urban & 44 & 88.0 \\
\hline & & Rural & 6 & 12.0 \\
\hline \multirow[t]{4}{*}{4.} & \multirow[t]{4}{*}{ Marital status } & Single & 5 & 10.0 \\
\hline & & Married & 40 & 80.0 \\
\hline & & Widow & 4 & 8.0 \\
\hline & & Divorced & 1 & 2.0 \\
\hline \multirow[t]{8}{*}{5.} & \multirow[t]{8}{*}{ Level of Education } & Illiterate & 5 & 10.0 \\
\hline & & Read \&write & 3 & 6.0 \\
\hline & & primary Graduate & 15 & 30.0 \\
\hline & & Intermediate Graduate & 10 & 20.0 \\
\hline & & secondary Graduate & 6 & 12.0 \\
\hline & & Diploma Graduate & 3 & 6.0 \\
\hline & & College Graduate & 7 & 14.0 \\
\hline & & Master Graduate & 1 & 2.0 \\
\hline \multirow[t]{5}{*}{6.} & \multirow[t]{5}{*}{ occupation } & Govern. employee & 11 & 22.0 \\
\hline & & Free job & 2 & 4.0 \\
\hline & & Retired & 1 & 2.0 \\
\hline & & Housewife & 35 & 70.0 \\
\hline & & Students & 1 & 2.0 \\
\hline \multirow[t]{3}{*}{8.} & \multirow[t]{3}{*}{ Monthly Income } & Sufficient & 16 & 32.0 \\
\hline & & Barely sufficient & 19 & 38.0 \\
\hline & & Not Sufficient & 15 & 30.0 \\
\hline
\end{tabular}


Table(1) revealed that $96 \%$ of the study samples were females, more age (28-37)years old for hypothyroidism, high percentage of them were primary graduated hypothyroidism $30 \%$, $70 \%$ of them were housewife for hypothyroidism, $(88 \%)$ study sample from urban setting and $38 \%$ have barely sufficient income for hypothyroidism .

Table (2): Distribution of Patients and Family according to HypothyroidismRelated to Clinical History.

\begin{tabular}{|l|l|l|l|}
\hline \multirow{2}{*}{ List } & Clinical history & \multicolumn{2}{|l|}{} \\
\cline { 3 - 4 } & & Freq. & percent \\
\hline $\mathbf{1}$ st & Clinical history for patient & & \\
\hline $\mathbf{1}$ & High cholesterol in the blood & 6 & 12.0 \\
\hline $\mathbf{2}$ & Heart disease & 8 & 16.0 \\
\hline $\mathbf{3}$ & Hypertension & 15 & 30.0 \\
\hline $\mathbf{4}$ & Previous surgery of thyroid gland & 12 & 24.0 \\
\hline $\mathbf{5}$ & Diabetes mellitus & 5 & 10.0 \\
\hline $\mathbf{6}$ & Use of radioactive iodine & 6 & 12.0 \\
\hline $\mathbf{7}$ & rheumatoid arthritis & 26 & 52.0 \\
\hline $\mathbf{2}^{\text {nd }}$ & Clinical history for family & 28 & 56.0 \\
\hline
\end{tabular}

Table (2) shows thathighest percentage (56\%) had rheumatoid arthritis as past medical history and $56 \%$ of patients had family history of hypothyroidism

Table (3): Diet and psychological domain for adult patientswithHypothyroidism.

\begin{tabular}{|c|c|c|c|c|c|c|}
\hline No. & Items & Daily & Weekly & Monthly & M.S & ASS. \\
\hline 1st & Diet domain & & & & & \\
\hline 1 & Meat (liver) & 7 & 21 & 22 & 2.3 & $\mathrm{M}$ \\
\hline 2 & Fish ,chicken and dairy products & 33 & 12 & 5 & 1.44 & $\mathrm{~L}$ \\
\hline 3 & Milk & 17 & 7 & 26 & 2.18 & $\mathrm{M}$ \\
\hline 4 & Cheese & 30 & 8 & 12 & 1.64 & $\mathrm{~L}$ \\
\hline 5 & Butter & 5 & 4 & 41 & 2.72 & $\mathrm{H}$ \\
\hline 6 & Lettuce & 36 & 5 & 9 & 1.46 & $\mathrm{~L}$ \\
\hline 7 & Spanish & 24 & 12 & 14 & 1.8 & $\mathrm{M}$ \\
\hline 8 & Green pepper & 23 & 8 & 19 & 1.92 & $\mathrm{M}$ \\
\hline 9 & Pineapple & 6 & 4 & 40 & 2.68 & $\mathrm{H}$ \\
\hline 10 & Raisins & 14 & 4 & 32 & 2.36 & $\mathrm{M}$ \\
\hline 2nd & Psychological domain & Always & Sometimes & never & M.S & ASS \\
\hline 1 & Feel my sleep turbulent and disturbance & 26 & 10 & 14 & 1.76 & M \\
\hline 2 & Feel nervous. & 36 & 8 & 6 & 1.4 & $\mathrm{~L}$ \\
\hline 3 & Feel disturbing dreams (nightmares). & 25 & 10 & 15 & 1.8 & $\mathrm{M}$ \\
\hline 4. & Feel distress of stomach. & 31 & 5 & 14 & 1.66 & $\mathrm{~L}$ \\
\hline 5 & Feel tired quickly. & 42 & 2 & 6 & 1.28 & $\mathrm{~L}$ \\
\hline 6 & Discomfort feeling when you wait. & 38 & 5 & 7 & 1.38 & $\mathrm{~L}$ \\
\hline 7 & Concentrate thinking in action. & 30 & 11 & 9 & 1.58 & $\mathrm{~L}$ \\
\hline 8 & Sweating in cold days. & 31 & 5 & 14 & 1.66 & $\mathrm{~L}$ \\
\hline 9 & Headache & 27 & 20 & 3 & 1.52 & $\mathrm{~L}$ \\
\hline 10 & Feeling anxiety from things are worthless. & 33 & 9 & 8 & 1.5 & $\mathrm{~L}$ \\
\hline 11 & A tense person & 34 & 7 & 9 & 1.5 & $\mathrm{~L}$ \\
\hline 12 & Feel sad. & 36 & 7 & 7 & 1.42 & $\mathrm{~L}$ \\
\hline 13 & Feel pessimistic about the future. & 13 & 8 & 29 & 2.32 & $\mathrm{M}$ \\
\hline 14 & Disappointed in myself. & 10 & 10 & 30 & 2.4 & $\mathrm{H}$ \\
\hline 15 & Lose my interest in people. & 16 & 8 & 26 & 2.2 & $\mathrm{M}$ \\
\hline 16 & Working the same efficiency. & 17 & 5 & 28 & 2.22 & $\mathrm{M}$ \\
\hline 17 & Normal sleep pattern. & 13 & 5 & 32 & 2.38 & $\mathrm{M}$ \\
\hline 18 & Tired more quickly than usual. & 45 & 2 & 3 & 1.16 & $\mathrm{~L}$ \\
\hline 19 & My appetite is not as good as before. & 22 & 8 & 20 & 1.96 & $\mathrm{~L}$ \\
\hline
\end{tabular}

M.s=mean of score $(1-1.69=$ low, $1.7-2.39=$ moderate, $2.4-3=$ high $)$

Table(3)shows that the mean of score are high on items $\left(1^{\text {st }}(5,9), 2^{\text {nd }}(14)\right.$, moderate and low on the remaining items.

Table (4): Social and medication domain for adult patients withHypothyroidism.

\begin{tabular}{|l|l|l|l|l|l|l|}
\hline 3rd & Social domain & Always & Sometimes & never & M.S & ASS \\
\hline 1 & Do take advantage of your free time? & 18 & 11 & 21 & 2.06 & M \\
\hline 2 & Participate in social activities & 34 & 5 & 11 & 1.54 & L \\
\hline 3 & Do you like to be relationships with others? & 43 & 4 & 3 & 1.2 & L \\
\hline 4 & Do you deal easily with your colleagues ? & 42 & 5 & 3 & 1.22 & L \\
\hline 5 & Are increasing problems during menstrual ? & 10 & 5 & 35 & 2.5 & H \\
\hline 6 & Feel anxiety when you stay at home. & 4 & 38 & 8 & 2.08 & M \\
\hline 7 & Prefer to stay at home away . & 2 & 24 & 24 & 2.44 & H \\
\hline
\end{tabular}




\begin{tabular}{|l|l|l|l|l|l|l|}
\hline 4 rh & Medication domain & Always & Sometimes & never & M.S & ASS \\
\hline 1 & Antacids drugs & 15 & 11 & 24 & 2.18 & M \\
\hline 2 & Iron and product & 6 & 18 & 26 & 2.4 & H \\
\hline 3 & Contraceptive drugs & 7 & 18 & 25 & 2.36 & M \\
\hline 4 & Sedatives and opiates & 8 & 17 & 25 & 2.34 & M \\
\hline 5 & Anti-thyroid drugs & 2 & 3 & 45 & 2.86 & H \\
\hline 6 & Cardiovascular drugs & 9 & 10 & 31 & 2.44 & H \\
\hline 7 & Diuretic drugs & 3 & 3 & 44 & 2.82 & H \\
\hline
\end{tabular}

M.s=mean of score(1-1.69= low, 1.7-2.39= moderate, $2.4-3=$ high $)$

Table(4)shows that the mean of score are high on items $3^{\text {rd }}(5,7), 4^{\text {th }}(2,5,6,7)$,moderate and low on the remaining items.

Table (5) Correlation coefficient between (gender, age, level of education) withrisk factors domains for hypothyroidism patients.

\begin{tabular}{|c|c|c|c|c|}
\hline Correlations & Gender & Age(years) & Level of education & Risk factors \\
\hline Gender & 1 & .101 & .058 & $\begin{array}{l}-.162- \\
\end{array}$ \\
\hline Age(years) & .101 & 1 & $-.136-$ & .028 \\
\hline Level of education & .058 & $-.136-$ & 1 & .144 \\
\hline Risk factors & $-.162-$ & .028 & .144 & 1 \\
\hline
\end{tabular}

This table (5) show that there is week negative relationship between contributing factors with gender $(\mathrm{r}=-.162-)$, and there is positive moderate relationship between contributing factors with level of education $(\mathrm{r}=.144)$, there is relationship between contributing factors with age $(\mathrm{r}=.028)$.

\section{Discussion}

Through the course of the data analysis of the presentstudy,the finding showed that the majority of the study samples for hypothyroidism $(96 \%)$ females ,(32\%) were (28-37) years old.This finding agree with other researcher who stated that diagnosed hypothyroidism was( $2.5 \%$ ) in females and $(0.6 \%)$ in males, hypothyroidism $(4.8 \%)$ in females and $(0.9 \%)$ for males ${ }^{(5)}$.

Seventy percentof thestudy samples groupishousewife as occupation andThirty eight percentare barely sufficient for hypothyroidism as monthly income.

This finding disagrees with other researcher who reported thata very high percentage $(54.4 \%)$ of the patients with thyroid disease is disability retired ${ }^{(6)}$.

Regarding residence, majority $(88 \%)$ of the study was urban for hypothyroidism. This finding were in good agreement with that obtain by other researcher which reported that the finding of participants had (19\%) participants from urban areas, $(81 \%)$ participants from rural areas ${ }^{(7)}$.

The finding of the study sample shows that (44\%) of thepatient had family history for hypothyroidism. This findings can be supported by another study the findings who reported that there wasno significant difference between those who had history of thyroid problem in their family and those who did not have history of thyroid problem in their family in cases as well as in control group ${ }^{(8)}$.

The result of accurate study that show diet domain in table(3)for hypothyroidism patients are high effect in (butter and pineapple).The mean of score is low effect in (white meat), (Cheese) and (Lettuce). The mean of score is moderate effect in( Red meat),(Milk), (Spanish) and (Green pepper). The finding of the diet domains show that moderate effect for hypothyroidism patient. The researcher believes diet domain the patient have bad dietary habit and no had diet information about nutrition value that effect on health statues.

This finding can be supported by another study the findings which reported that we get iodine from foods (butter, pineapple) and it is found in commercially processed iodized salt and preservatives used in bread products. High iodine can inhibit thyroid hormone production by increasing cellular resistance to T3 and may Lead to iodine induced thyroid deficiency, swelling, tenderness and goiter ${ }^{(9)}$.

Our finding about psychologicaldomain are similar to those reported that of the other researcher who stated there was predominance of Major depressive disorder $24.2 \%$, followed by anxiety disorders $(23 \%)$. The p-value of the comparison between the case and the control patients is 0.0001 which is highly significant ${ }^{(10)}$.

The mean of score of social domain in table (4) for hypothyroidism patients are high on item (Are increasing problems during menstrual cycle days?) and item (Prefer to stay at home away from the eyes of the people). The mean of score is moderate item(Do take advantage of your free time?), item(Feel anxiety when you stay at home) and low on the remaining items. This finding agrees with other researcher which reported that the 
patients of thyroid disease were significantly more anxious and perceived higher social support from family when compared with the control group ${ }^{(11)}$.

The mean of score of medication domain in table (4) for hypothyroidism patients are high on item(Iron and product), item(Anti-thyroid drugs), item(Cardiovascular drugs) and item (Diuretic drugs) .The mean of score is moderate item(Antacids drugs), item(Contraceptive drugs) and item(Sedatives and opiates).

These result were similar to those result obtained by other researcher who stated that many different drugs affect thyroid function. Most of these medication act at the level of the thyroid in patients with normal thyroid function, or at the level of thyroid hormone absorption or metabolism in patients requiring exogenous levothyroxine ${ }^{(12)}$.

The findings of the study sample hypothyroidism patients indicated that there is weak negative relationship between contributing factors with gender $(\mathrm{r}=-.162-)$, and there is weak positive relationship between contributing factors with level of education( $(\mathrm{r}=.144)$, there is no relationship between contributing factors with age $(\mathrm{r}=.028)$.Table (5)

\section{Conclusions}

Our data indicate that the contributing factors domains of patients with hypothyroidism is moderate decline in all domains expect medication domain is high of risk factors domains.

\section{Recommendation}

Based on the results and conclusions of the present study; the researcher recommends the following:

1. Established the new department for early detection hypothyroidism and hyperthyroidism for adult patient.

2. Education program for nurses to improve the patient quality of life.

\section{References}

[1] Garber, JR., Cobin, RH.,Gharib, H, Hennessey, JV., Klein, I., Mechanick, JI,. Pessah-Pollack, R., Singer, PA., Woeber,: KA for the American Association of Clinical Endocrinologists and the American Thyroid Association Taskforce on Hypothyroidism in Adults. "Clinical Practice Guidelines for Hypothyroidism in Adults".Thyroid,Vol.22,NO.12,(2012),P.P:1200-1235.

[2] Huether, S., \&McCance, K.: Understanding Pathophysiology (4th ed.),(2007), St. Louis:Mosby.

[3] Cooper, DS.,Braverman, LE.,: Werner \&Ingbar's the thyroid : a fundamental and clinical text (10th ed.). Philadelphia: Wolters Kluwer/Lippincott Williams \& Wilkins Health. (2012), P. 552. ISBN 145112063X

[4] Patrici, A.;American Thyroid Association. "Hypothyroidism." Clinical Thyroidology for Patients. 2:3. (2009). 30 Sept 2009 <http://thyroid.org/patients/ct/volume2/issue3/ct_patients_v23_5.html>.

[5] Bjùro T., Holmen, J., Krue,E. , Midthjell,K., et. al,: Prevalence of thyroid disease, thyroid dysfunction and thyroid peroxidase antibodies in a large, unselected population. The Health Study of Nord-Trùndelag (HUNT), European Journal of Endocrinology, Vol.143, (2000) ,pp. 639-647.

[6] Vasile, P.; Screening and psychological evaluation of patients with thyroid dysfunction, "Babeș-Bolyai” University Cluj-Napoca faculty of psychology and educational Sciences ,2011.p.p.11.Viruses and thyroiditis; update, Rachel Desailloud and Didier Hober, Virology Journal ,Vol.6,(2009), P.5.

[7] Munifa, Toto, S. , Untung, S., Widodo.: Eating pattern and smoking as risk factors for hyperthyroidism .public health postgraduate program faculty of medicine gadjahmada university yogyakarta.(2011), NIM: 09/293533/PKU/11009.

[8] Raghda, A.; Assessment of Thyroid Function in Pregnant Women From Rimal Health Center, Gaza City, The Islamic UniversityGaza ,deanery of higher education ,faculty of Science, master of biological sciences, medical technology12\2010-1 $\backslash 1432$

[9] Brinker, Francis. Herb Contraindications \& Drug Interactions. $3^{\text {rd }}$ Ed. Sandy, OR: Eclectic Medical Publications, 2001.

[10] Sheikh, S., Raheel, M., Mohammad, M., Tasleem, A.; Psychiatric Manifestations in thyroid disorders, International Journal of Clinical Cases and Investigations. Vol.5, NO. 3, (2013), P.P:84:98.

[11] Petra M.; Psychosocial Factors in Patients with Thyroid Disease, Thyroid and Parathyroid Diseases -New Insights into Some Old and Some New Issues, Dr. Laura Ward (Ed.), ISBN: 978-953-51-0221-2012.

[12] Deborh, m.,:clinical expression, pathophysiology consequences and general health status in elderly individuals with subclinical thyroid dysfunction, University of Birmingham Research Archive, June 2011. 